\title{
Resistant Palmoplantar Lesions in Patients of Psoriasis: Evaluation of the Causes and Comparison of the Frequency of Delayed-Type Hypersensitivity in Patients without Palm and Sole Lesions
}

\author{
Nawaf Al-Mutairia Tarek O. Abdalla ${ }^{b}$ Tarek M. Nour ${ }^{b}$ \\ ${ }^{a}$ Department of Medicine, Faculty of Medicine, Kuwait University, and ${ }^{\text {b}}$ Department of Dermatology, Farwaniya \\ Hospital, Farwaniya, Kuwait
}

\section{Key Words}

Allergic contact dermatitis - Palmoplantar psoriasis .

Patch test

\begin{abstract}
Objective: To examine the reasons for resistance to treatment in cases of palmoplantar psoriasis, and also to compare the frequency of delayed-type hypersensitivity to common sensitizers with those cases of psoriasis without palmoplantar involvement. Subjects and Methods: One hundred and three patients with resistant palmoplantar psoriasis were examined for a possible drug reaction, fungal infection or contact allergy. Patch testing was done for another 100 patients with psoriasis vulgaris without palm and sole involvement. $X^{2}$, Fischer's exact test, Mann-Whitney $U$ test and logistical regression analysis were done using SPSS 15.0. Results: Of the 103 patients with resistant palmoplantar lesions, 26 (25.24\%) had a positive patch test to at least one of the tested allergens, $6(5.8 \%)$ had psoriasiform spongiotic dermatitis on biopsy, $5(4.8 \%)$ reported exacerbation after starting biologic therapy and $3(2.9 \%)$ were potassium hydroxide positive in the sole lesions. In comparison, of the 100 patients
\end{abstract}

with no palm or sole lesions, $11(11 \%)$ had a positive patch test to at least one of the allergens. There was a direct relationship between the increase in the prevalence of dermatitis and the duration of psoriasis. There was no correlation between the clinical type of psoriasis and patch-test positivity. Conclusion: Secondary fungal infection, allergic contact dermatitis to topical agents or common allergens, or at times an unusual reaction to the antipsoriatic therapeutic agents sometimes led to treatment failure in patients with psoriasis vulgaris with palmoplantar lesions. Also, psoriasis patients with palm and sole lesions tended to have higher rates of contact hypersensitivity than patients without lesions on their palms and soles.

(C) 2014 S. Karger AG, Basel

\section{Introduction}

Psoriasis is a common chronic T cell-mediated inflammatory disease that frequently presents as long-lasting, sharply defined, raised, dull red, scaly plaques, mostly on the extensor prominences and scalp. It is considered an immunological disease, which is characterized by dermal

\begin{tabular}{ll}
\hline KARGER & $\begin{array}{l}\text { ๑ 2014 S. Karger AG, Basel } \\
\text { 1011-7571/14/0236-0561\$39.50/0 Open carger }\end{array}$ \\
E-Mail karger@karger.com & $\begin{array}{l}\text { Thisis an Open Access article licensed under the terms of the } \\
\text { www.karger.com/mpp }\end{array}$ \\
& $\begin{array}{l}\text { Creative Commons Attribution-NonCommercial 3.0 Un- } \\
\text { ported license (CC BY-NC) (www.karger.com/OA-license), } \\
\text { applicable to the online version of the article only. Distribu- } \\
\text { tion permitted for non-commercial purposes only. }\end{array}$
\end{tabular}

Dr. Nawaf Al-Mutair

Department of Medicine

Faculty of Medicine, Kuwait University

PO Box 280, Farwaniya 80000 (Kuwait)

E-Mail nalmut@usa.net 
inflammation with secondary epidermal hyperplasia [1]. Unfortunately, no permanent remedy for this disease has been found. However, the spectrum of therapeutic modalities for temporary remission of this disease continues to expand [2]. Typically, topical agents are the first-line therapy for most psoriasis patients. Even in the few patients in whom topical agents are not the first choice, they are still used as an adjuvant.

Palmoplantar lesions in psoriasis are usually very resistant to treatment [3]. This could be due to the greater thickness of the involved skin, which makes it difficult for the topical agents to penetrate, or koebnerization triggered by repeated trauma (seen in about $50 \%$ of cases). Because of the recalcitrant nature, easy visibility and location on functionally exposed parts, the condition can lead to disability [4] and significant psychological effects $[5,6]$ in many patients. The relationship between psoriasis and allergic contact dermatitis (ACD) is still a matter of argument. Several studies [7-10] have shown that patients with psoriasis have a higher incidence of ACD to common sensitizers, as well as to the topical agents used for treatment. However, there are a few studies which have shown contrasting results and have concluded that the rate of patch-test positivity is reduced in patients with psoriasis $[11,12]$. Nevertheless, extended and excessive use of numerous topical agents to treat resistant lesions on palms and soles does make these patients susceptible to developing contact hypersensitivity to the topical agents. In addition, the location of the lesions also increases the risk of sensitization to other common contact sensitizers due to an altered skin barrier. Recently, biological drugs used for the treatment of psoriasis have been shown to result in psoriasiform dermatitis on palms and soles $[13,14]$, which, when not recognized, may be mistaken for psoriasis. Furthermore, there are a few case reports of the occurrence of new lesions of psoriasis after starting biologic therapy in patients with inflammatory bowel disease [15] or even in cases of psoriasis [16]. Also, the prolonged use of topical steroids on soles can lead to secondary fungal infections [17].

ACD is characterized by a complex immunological mechanism which presents as a delayed (48-96 h) type IV hypersensitivity reaction, primarily mediated by $\mathrm{T}$ and antigen-presenting cells. Contact hypersensitivity consists of two distinct phases, a sensitization phase and an elicitation phase. The sensitization phase includes the events following first contact with a hapten, by which an individual becomes sensitized due to the development of immunological memory. The sensitization phase is usually symptomless and typically lasts about 10-15 days.
The elicitation phase begins when a sensitized individual is reexposed to the hapten, and memory $\mathrm{T}$ cells are recruited to the skin leading to clinical manifestation of $\mathrm{ACD}$; this phase typically takes $72 \mathrm{~h}$, but this may vary $[18,19]$.

Patch tests consist of a series of properly formulated low-molecular-weight substances (hapten) diluted in a solid or aqueous vehicle and contained in small reservoirs on a support that is kept in place by an occlusive plaster in order to confirm contact with the skin for $48 \mathrm{~h}$. The $\mathrm{ACD}$ is a delayed hypersensitivity, as the reaction tends to present 48-96 h after the contact of the hapten, but even further delays of up to 3 weeks have been noticed $[20,21]$.

The current study was conducted to evaluate the causes of treatment failure of palm and sole lesions in psoriasis patients. A further aim was to compare the rate of contact hypersensitivity in psoriasis patients with palm and sole lesions with those without any such lesions.

\section{Subjects and Methods}

Of the total of 1,019 patients with psoriasis who had consulted the Dermatology Outpatient Clinics, Farwaniya Hospital, Kuwait, between January 2011 and January 2013, 103 (10.1\%) complained of persistent or new lesions on their palms and/or soles while on treatment for at least 4 weeks. These 103 patients constituted group A (62 male, 41 female). The diagnosis of psoriasis was made mostly on the basis of clinical examination, and only in a few difficult cases was dermatopathologic correlation required. A dermatologic examination was done on the first visit to estimate the type and extent of psoriasis. Based on the clinical pattern, these patients were divided into 3 subgroups: psoriasis vulgaris ( $n=42 ; 23$ male, 19 female), guttate psoriasis $(n=16$; 9 male, 7 female) and inverse psoriasis ( $n=45$; 30 male, 15 female). The age range was $15-71$ years, with a median value of 37.7. The following basic data were noted in all the 103 patients: age, sex, present occupation, histories of atopy, contact dermatitis, topical skin care, cosmetic usage, medications and use of gloves. All 103 patients were also evaluated for fungal infection, drug reaction and contact hypersensitivity using a potassium hydroxide $(\mathrm{KOH})$ test, biopsy of the lesion using 5-mm disposable punches and a patch test.

In addition, 100 patients with psoriasis (group B; 51 male, 49 female) seen during the same period in our outpatient clinics, who did not have involvement of the palm and sole, were also patch tested. They constituted the control group. Patch testing in these patients was also done using the same guidelines as previously described.

A written informed consent was obtained from all the patients before the patch test was carried out. Exclusion criteria were psoriasis on the back, which makes patch testing difficult, pregnancy, pustular psoriasis and treatment with systemic corticosteroids, cytotoxic or immunosuppressive agents. All these patients were patch tested on the upper back according to international stan- 
Table 1. Demographic and clinical details of the patients in both groups

\begin{tabular}{llcc}
\hline Factors & $\begin{array}{l}\text { Group A } \\
(\mathrm{n}=103)\end{array}$ & $\begin{array}{l}\text { Group B } \\
(\mathrm{n}=100)\end{array}$ & p value \\
\hline Mean age, years & 37.43 & 36.33 & n.s. \\
Sex (M/F) & $62 / 41$ & $59 / 41$ & n.s. \\
Mean age at presentation, years & 33.63 & 31.51 & \\
History of contact sensitivity, $\mathrm{n}$ & $3(2.9 \%)$ & $2(2 \%)$ & \\
Clinical type of psoriasis & $42(23 / 19)$ & $43(27 / 16)$ & \\
$\quad$ Plaque, $\mathrm{n}$ & $16(9 / 7)$ & $15(7 / 8)$ & \\
$\quad$ Guttate, $\mathrm{n}$ & $45(30 / 15)$ & $39(22 / 17)$ & $<.0 .001$ \\
$\quad$ Inverse, $\mathrm{n}$ & 4.34 & 4.22 & \\
Mean PASI scores & $26(11 / 15 ; 25.24 \%)$ & $11(4 / 7 ; 11 \%)$ & $<$ \\
Patch-test positive, $\mathrm{n}$ & & \\
\hline
\end{tabular}

Where relevant, results are divided by sex $(\mathrm{M} / \mathrm{F})$. n.s. $=$ Not significant; PASI $=$ psoriasis area and severity index.

dards and using the following series: the TRUE Test series (TRUE Test $^{\circledR}$, MEKOS Laboratories ApS, Hillerod, Denmark) panels 1 and 2 , and a topical psoriasis treatment patch-test series, including a corticosteroid series.

The TRUE Test (thin-layer rapid-use epicutaneous test) is a ready-to-use patch-test system for diagnosis of ACD. TRUE Test series were applied directly. The psoriasis patch-test series were prepared in collaboration with the Department of Pharmacy or tested 'as is' and applied using Finn Chambers for occlusion. All test results were read after 2 and 3 days, and the corticosteroid series were read again after 5 days. The tests were scored as follows: redness, +; redness and papules, ++; redness, papules and vesicles, +++ , and reaction with eczema beyond the boundary of the test area, ++++ .

The patients were instructed to wear the patch-test panels for a minimum of $48 \mathrm{~h}$ without removing them, and were instructed not to get the test area wet (e.g. with water or sweat). Reactions were monitored on the day the patch was removed after $48 \mathrm{~h}$ (day 2), then at $96 \mathrm{~h}$ (day 4), and the corticosteroid series were read again after 5 days. Suspicious reactions, showing persistent reactions of the same or an amplified score on day 7 or later, were considered allergic and were counted.

A complete clinical history based on the test result and evaluation of the patient's chemical surroundings was done for the correct assessment of relevance. Irritant reactions were diagnosed by the typical clinical criteria and were excluded.

Patients were not allowed to apply any topical agents to the patch-test sites for 1 week before the application of the test. Only emollients were allowed to be used on the test area for at least 3 days before testing, while systemic therapy and phototherapy were stopped 1 week before the test commenced. Any patient who had a positive reaction was given advice about the contact substance, with information on avoidance and protection.

Statistical Analysis

$\chi^{2}$ and Fischer's exact tests were used to compare the categorical data, represented as numbers and percentages, and the Mann-
Whitney U test was used to compare continuous data, summarized as means and ranges between the two groups. A logistical regression model was used to test the association between various demographic factors and clinical characteristics. The SPSS statistical software package (v.15.0) was used for the analysis of the data.

\section{Results}

Of the 103 patients, involvement of both palms and soles was seen in 67 (65\%), only palms in 14 (13.6\%), and only soles in $22(21.3 \%)$. Fifteen (14.5\%) patients had vesiculopustular lesions on their palms and/or soles. The demographic profile of the patients is shown in table 1 . Potassium hydroxide preparation examination was positive in $3(2.9 \%)$ patients, and in all 3 it was positive in the sole lesions. Skin biopsy was compatible with the clinical diagnosis of psoriasis in 97 (94\%), and in 6 (5.8\%) patients the biopsy revealed psoriasiform spongiotic dermatitis. Of the 6 patients with histopathological psoriasiform spongiotic dermatitis, 3 were positive after scraping for fungus, and the other 3 were on biologic therapy. Of the 103 patients, $5(4.85 \%)$ reported the appearance of lesions on palms and/or soles after starting biologic therapy for moderate-to-severe body lesions. Of these 5 patients, 2 were started on infliximab, 2 on adalimumab and 1 on etanercept, respectively (fig. 1).

Out of the 103 patients in group A, 26 (25.2\%) had a positive patch test to at least one of the tested sensitizers. There were more positive outcomes among females than males (15 females, $36.5 \%$, vs. 11 males, $17.7 \%$ ). On further 
Fig. 1. Spectrum of causes of treatment failure identified in group A patients.

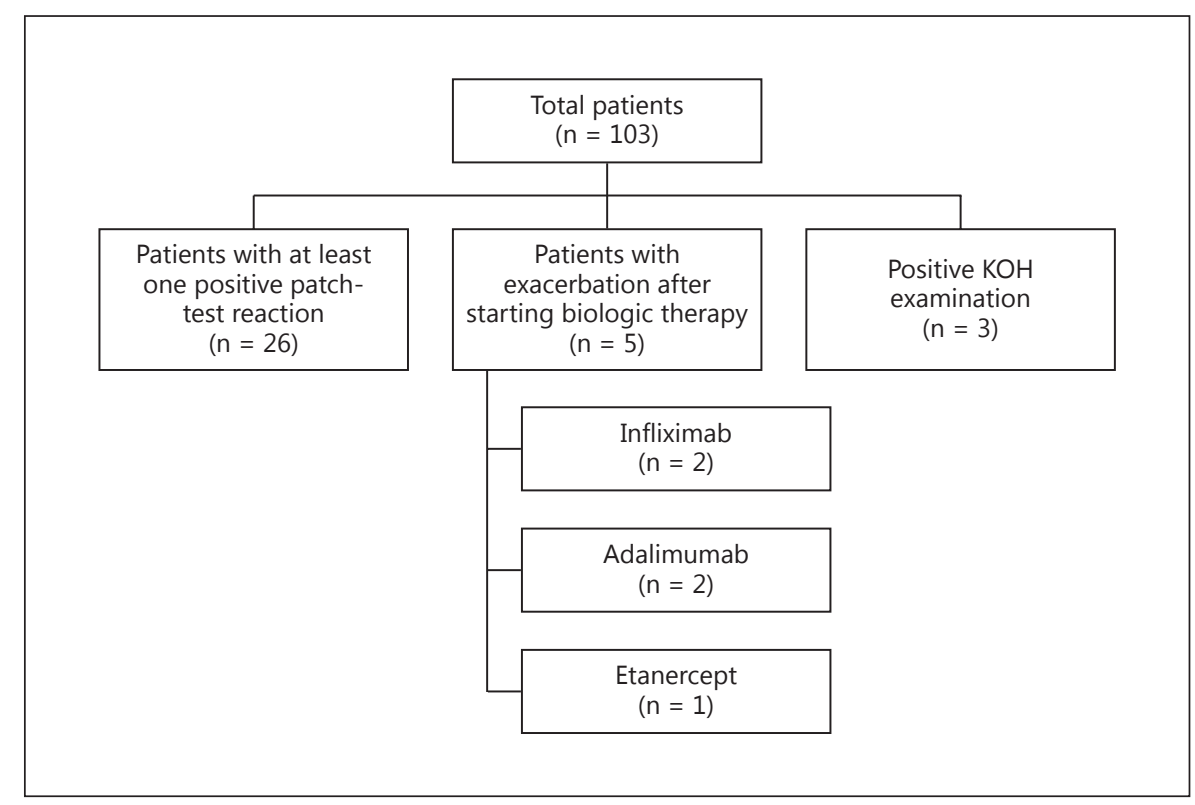

analysis of patients in group A according to the clinical type of psoriasis, we found that, of the 42 patients with psoriasis vulgaris, 12 (5 male, 7 female) had one or more positive patch test. Among the cases with guttate psoriasis, 3 ( 2 male, 1 female) had one or more positive patch test. Finally, of the 45 cases with inverse psoriasis, 11 (4 male, 7 female) had one or more positive patch tests.

Of the 103 patients in group A, a past history suggestive of contact sensitivity was present in 3 (2.9\%), while of the 100 patients in group B, this was the case for $2(2 \%)$. There was a direct relationship between the increase in the prevalence of dermatitis and the time since the clinical onset of psoriasis. Patients with a history of psoriasis of more than 3 years were associated with a higher rate of positive patch test compared with a shorter disease duration ( $\mathrm{p}<0.001$; OR 0.581; 95\% CI 0.494-0.684).

A summary of the substances that were positive in patch tests is shown in table 2. There was no correlation between the clinical type of psoriasis and patch-test positivity. The 5 most frequent sensitizers were nickel sulfate, fragrance mix, $p$-phenylenediamine, coal tar, and black rubber mix. Multisensitization was more frequent among women. The mean psoriasis area and severity index in patch test-negative psoriatic patients was 5.73 , while the mean psoriasis area and severity index in patch test-positive psoriatic patients was 4.28 . The difference was not statistically significant $(\mathrm{p}>0.001)$.

The patch-test results in the comparative group of 100 patients of psoriasis without involvement of palms and soles revealed 11 patients with positive patch-test results to at least one tested sensitizing substance. The details of the patch-test results are presented in table 2.

\section{Discussion}

In this study, the frequency of psoriasis patients with palmoplantar lesions who presented with contact hypersensitivity to at least one contact was higher $(25.2 \%)$ than of those without palm and sole involvement (11\%). This finding is within the previously reported range of $20-25 \%$ of psoriasis patients having palm and sole involvement $[22,23]$. However, Fransson et al. [17] reported a lower positive patch-test rate of $17 \%$, while Lipozencić et al. [24] reported a much higher rate of $41.7 \%$ in psoriasis patients with palmoplantar involvement, and a much lower rate of $6.6 \%$ for those without palm and sole involvement. The most common contact sensitizers found in their study were nickel sulfate, mercapto mix, balsam of Peru, potassium dichromate, mercury mix and fragrance mix. However, few studies $[7,10,25]$ have indicated that the site of lesions displayed no correlation with patch-test positivity.

A probable explanation for the differences in these studies could be the formation of new lesions in the course of the disease, or the exacerbation of current lesions and/ or resistant treatment in some patients due to the association of local triggering factors that may include infections, drug reaction, contact dermatitis to common sen- 
Table 2. Details of the positive patch-test reactions in both groups

\begin{tabular}{|c|c|c|c|}
\hline \multirow[t]{2}{*}{ Name of test } & \multicolumn{3}{|c|}{ Positive results, $\mathrm{n}$} \\
\hline & group A & group B & total \\
\hline \multicolumn{4}{|l|}{ True test series } \\
\hline Nickel sulfate & 9 & 4 & 13 \\
\hline Fragrance mix & 9 & 4 & 13 \\
\hline Potassium dichromate & 2 & 3 & 5 \\
\hline Cobalt chloride & 1 & 2 & 3 \\
\hline$p$-Phenylenediamine & 5 & 3 & 8 \\
\hline Thiomersal & 1 & 0 & 1 \\
\hline Neomycin sulfate & 0 & 0 & 0 \\
\hline Paraben mix & 0 & 0 & 0 \\
\hline Colophony & 1 & 1 & 2 \\
\hline Epoxy resin & 0 & 0 & 0 \\
\hline Black rubber mix & 2 & 0 & 2 \\
\hline Mercapto mix & 0 & 0 & 0 \\
\hline Quinoline mix & 0 & 0 & 0 \\
\hline Balsam of Peru & 2 & 1 & 3 \\
\hline Wool alcohols (lanolin) & 0 & 0 & 0 \\
\hline Formaldehyde & 1 & 0 & 1 \\
\hline Caine mix & 1 & 0 & 1 \\
\hline Ethylenediamine dihydrochloride & 1 & 0 & 1 \\
\hline Thiuram mix & 0 & 0 & 0 \\
\hline$p$-Tert-butylphenol formaldehyde resin & 1 & 0 & 1 \\
\hline Mercaptobenzothiazole & 0 & 0 & 0 \\
\hline Carba mix & 2 & 0 & 2 \\
\hline Quaternium-15 & 0 & 0 & 0 \\
\hline $\mathrm{Cl}+$ Me-isothiazolinone (Kathon CG) & 0 & 0 & 0 \\
\hline \multicolumn{4}{|l|}{ Psoriasis series } \\
\hline Salicylic acid (1\%) in petrolatum & 0 & 0 & 0 \\
\hline Coal tar $(5 \%)$ in petrolatum & 5 & 2 & 7 \\
\hline Daivonex cream (calcipotriol 50 mg/g) & 0 & 0 & 0 \\
\hline Daivonex ointment (calcipotriol 50 mg/g) & 1 & 1 & 2 \\
\hline Mometasone furoate $(0.1 \%)$ & 0 & 0 & 0 \\
\hline Clobetasol ointment $(0.05 \%)$ & 4 & 2 & 6 \\
\hline Betamethasone valerate $(0.1 \%)$ & 2 & 1 & 3 \\
\hline Daivobet gel ( $50 \mu \mathrm{g} / \mathrm{g}$ calcipotriol/500 $\mu \mathrm{g} / \mathrm{g}$ betamethasone) & 0 & 0 & 0 \\
\hline Daivobet ointment ( $50 \mu \mathrm{g} / \mathrm{g}$ calcipotriol $/ 500 \mu \mathrm{g} / \mathrm{g}$ betamethasone) & 0 & 0 & 0 \\
\hline Total & 26 & 11 & 37 \\
\hline
\end{tabular}

sitizers or even topical medications used to treat the disease. ACD has been reported to be one of the significant factors, especially in cases with palmoplantar involvement [24]. Higher rates of ACD in patients of psoriasis with palmoplantar lesions could be due to a relatively higher risk of exposure to contact sensitizers because of the impairment of the cutaneous barrier function, leading to increased probabilities for absorption and secondary sensitization, and consequently to ACD. In this study, there was no significant difference in the frequency of contact hypersensitivity between the patients with different clinical scenarios of psoriasis, which is similar to the study of Fleming and Burden [7].

The $6.4 \%$ finding of nickel sulfate as the most common positive patch reaction in our study is similar to what has been reported previously $[7,25]$. Furthermore, fragrance mix and coal tar were the other reactions in psoriatic patients, which is also consistent with other studies [7, 10, 
23]. It is equally important to note that male psoriasis patients had a reduced reaction compared to female patients. A probable explanation could be that female patients were using more accessories and fragrance than male patients, thereby confirming the previous study that female psoriatic patients use many emollient creams and ointments which frequently contain fragrances [10].

The finding that there was no association between the severity of disease and patch-test reactivity confirmed the study of Jovanović et al. [26], who also found no association between positive patch-test and psoriasis severity. Furthermore, the finding that the patch-test reactivity was increased with the longer duration of psoriasis is similar to that of Malhotra et al. [10], who observed a higher incidence of positive patch-test results in patients with a longer duration of disease ( 5 years). The patients with a longer duration of disease in our cohort reported having used a larger variety of medications than those with a recent onset of disease, as was also reported by Laurindo and Scheinberg [14]. There was a linear association between the increase in the frequency of dermatitis and the time since the clinical onset of psoriasis [27].

Seven positive patch-test results were associated with corticosteroid preparations. In many patients with 'longstanding' psoriasis unresponsive to topical corticosteroid therapy, contact sensitivity to corticosteroids was shown to be consistent with a previous study [28]. The frequency of sensitization correspondingly increased with the number of topical agents applied [27]. The extended use of multiple topical medicaments for psoriasis increases exposure to potential sensitizers. Contact sensitizers might help in aggravating and/or maintaining psoriatic lesions, particularly when mechanical factors are involved, as part of the Koebner phenomenon [23]. Profession-associated psoriasis has been most commonly ac- companied with frictional or pressure trauma, and an isomorphic (Koebner) response leading to new lesions of psoriasis [23]. ACD could act as a koebnerizing stimulus on a psoriatic background [29].

Heule et al. [30] tried to explain the reasons why psoriasis might be associated with ACD. Firstly, both psoriasis and ACD share an underlying T helper 1 cell immune mechanism. Secondly, ACD compromises the skin barrier function and diminishes the thickness of the epidermis overlying elongated dermal papillae, and the use of keratolytics might exaggerate the penetration of sensitizers [30]. A limiting factor of our study was the lack of similar data from the general population in our region for comparison.

\section{Conclusion}

Our study showed that hypersensitivity to contact sensitizers, especially in psoriasis patients with resistant palmoplantar lesions, was a relevant provoking/perpetuating factor in the clinical development of the disease. Patch testing with a standard patch-test series, an extended corticosteroid series, and also with the other topical antipsoriatic agents used by the patient could be included as a routine diagnostic procedure in resistant palmoplantar psoriasis patients. Avoidance of any relevant sensitizing substances identified may make patients of the resistant form of palmoplantar psoriasis more responsive to therapy.

\section{Disclosure Statement}

None.

\section{References}

1 Casanova JM, Marti RM: Inmunopatogénesis de la psoriasis. Piel 1993;7:486-495.

2 Graaves MV, Weinstein GD: Treatment of psoriasis. N Engl J Med 1995;332:581-587.

-3 Brunasso AMG, Puntoni M, Aberer W, et al: Clinical and epidemiological comparison of patients affected by palmoplantar plaque psoriasis and palmoplantar pustulosis: a case-series study. Br J Dermatol 2013;168:12431251.

-4 Pettey AA, Balkrishnan R, Rapp SR, et al: Patients with palmoplantar psoriasis have more physical disability and discomfort than patients with other forms of psoriasis: implica- tions for clinical practice. J Am Acad Dermatol 2003;49:271-275.

5 Farley E, Masrour S, McKey J, et al: Palmoplantar psoriasis: a phenotypical and clinical review with introduction of a new quality-oflife assessment tool. J Am Acad Dermatol 2009;60:1024-1031.

-6 Sampogna F, Tabolli S, Söderfeldt B, et al: Measuring quality of life of patients with different clinical types of psoriasis using the SF36. Br J Dermatol 2006;154:844-849.

7 Fleming CJ, Burden AD: Contact allergy in psoriasis. Contact Dermatitis 1997;36:274276.
8 Clark AR, Sherertz EF: The incidence of allergic contact dermatitis in patients with psoriasis vulgaris. Am J Contact Dermatol 1998; 9:96-99.

-9 Fransson J, Storgårds K, Hammar H: Palmoplantar lesions in psoriatic patients and their relation to inverse psoriasis, tinea infection and contact allergy. Acta Derm Venereol 1985;65:218-223.

10 Malhotra V, Kaur I, Saraswat A, et al: Frequency of patch-test positivity in patients with psoriasis: a prospective controlled study. Acta Derm Venereol 2002;82:432435 . 
11 Bangsgaard N, Engkilde K, Thyssen JP, et al: Inverse relationship between contact allergy and psoriasis: results from a patient- and a population-based study. Br J Dermatol 2009; 161:1119-1123.

12 Fedler R, Stromer K: Nickel sensitivity in atopics, psoriasis and healthy subjects. Contact Dermatitis 1993;29:65-69.

13 Osório F, Magro F, Lisboa C, et al: Anti-TNFalpha induced psoriasiform eruptions with severe scalp involvement and alopecia: report of five cases and review of the literature. Dermatology 2012;225:163-167.

14 Laurindo IM, Scheinberg M: Why do some biologic agents induce psoriasis or psoriasiform lesions? Nat Clin Pract Rheumatol 2008; 4:168-169.

15 Shale M, Ghosh S: Learning the lessons of antitumour necrosis factor therapy-associated psoriasis. Can J Gastroenterol 2009;23:674-676.

16 Joyau C, Veyrac G, Dixneuf V, et al: Anti-tumour necrosis factor alpha therapy and increased risk of de novo psoriasis: is it really a paradoxical side effect? Clin Exp Rheumatol 2012;30:700-706
17 Fransson J, Storgårds K, Hammar H: Palmoplantar lesions in psoriatic patients and their relation to inverse psoriasis, tinea infection and contact allergy. Acta Derm Venereol 1985;65:218-223.

18 Rustemeyer T, van Hoogstraten IMW, von Blomberg BM, et al: Mechanisms in allergic contact dermatitis; in Frosch PJ, Menné T, Lepoittevin JP (eds): Contact Dermatitis, ed 4. Berlin, Springer, 2006, pp 11-43.

19 Vocanson M, Hennino A, Rozières A, et al: Effector and regulatory mechanisms in allergic contact dermatitis. Allergy 2009;64:16991714 .

20 Militello G, Jacob SE, Crawford GH: Allergic contact dermatitis in children. Curr Opin Pediatr 2006; 18:385-390.

21 Jacob SE, Steele T, Brod B, et al: Dispelling the myths behind pediatric patch testing - experience from our tertiary care patch testing centers. Pediatr Dermatol 2008;25:296-300.

22 Pasic A, Lipozenic J, Kansky A, et al: Contact allergy in psoriatic patients with palmar and plantar lesions. Acta Derm Venereol Suppl 1989;146:66-68.

23 Caca-Biljanovska N, V'lckova-Laskoska M, Balabanova-Stefanova M, et al: Frequency of delayed-type hypersensitivity to contact allergens in palmo-plantar psoriasis. Prilozi 2005; 26:131-141.
24 Lipozencić J, Milavec-Puretić V, Pasić A: Contact allergy and psoriasis. Arh Hig Rada Toksikol 1992;43:249-254.

25 Barile M, Cozzani E, Anonide A, et al: Is contact allergy rare in psoriatics? Contact Dermatitis1996;35:113-114.

26 Jovanović M, Boza P, Karadaglić D, et al: Contact sensitivity in patients with psoriasis in Vojvodina. Int Arch Allergy Immunol 2009; 148:311-320.

27 Pigatto PD: Atopy and contact sensitization in psoriasis. Acta Derm Venereol Suppl (Stockh) 2000;211:19-20.

28 Burden AD, Beck MN: Contact hypersensitivity to topical corticosteroids. Br J Dermatol 1993; 127:497-500.

29 Hill VA, Ostlere LS: Psoriasis of the hands köbnerizing in contact dermatitis. Contact Dermatitis 1998;39:194.

30 Heule F, Tahapary GJ, Bello CR, et al: Delayed-type hypersensitivity to contact sensitizers in psoriasis: a clinical evaluation. Contact Dermatitis1998;38:78-82. 